\title{
Effect of Methyl Groups on the Thermal Properties of Polyesters from Methyl Substituted 1,4-Butanediols and 4,4'-Biphenyldicarboxylic Acid
}

\author{
ALBERT J. B. LOMAN,' LEEN VAN DER DOES, ${ }^{1}$ ADRIAAN BANTJES, ${ }^{1}$ and IVAN VULIC ${ }^{2, *}$ \\ 'Department of Chemical Technology, University of Twente, P. O. Box 217, 7500 AE Enschede, The Netherlands, \\ ${ }^{2}$ DSM Research, P. O. Box 18, 6160 MD Geleen, The Netherlands
}

\begin{abstract}
SYNOPSIS
Results are reported on the effect of lateral methyl groups on the thermal properties of a series of polyesters prepared from diethyl 4,4'-biphenyldicarboxylate and various methyl substituted 1,4-butanediols. The diols were 1,4-butanediol; 2-methyl-1,4-butanediol; 2,2dimethyl-1,4-butanediol; 2,3-dimethyl-1,4-butanediol; 2,2,3-trimethyl-1,4-butanediol; and 2,2,3,3-tetramethyl-1,4-butanediol. Apart from the tetramethyl derivative, the transition temperatures of the methyl substituted polyesters were lower with respect to the unsubstituted polyester. On the basis of polarized photomicrographs, a smectic A mesophase was found for the unsubstituted polyester, whereas a nematic mesophase was observed for the 2-methyl substituted polyester. The 2,2-dimethyl, 2,3-dimethyl, and the 2,2,3-trimethyl substituted polyesters showed no liquid crystalline behavior. The 2,2,3,3-tetramethyl derivative displayed a birefringent melt phase although the DSC measurements were not unambiguous. A copolyester based on diethyl 4,4'-biphenyldicarboxylate, 1,4-butanediol, and 2,2,3,3-tetramethyl-1,4-butanediol showed a broad nematic mesophase. Further evidence for the nematic mesophase of this copolyester and the 2-methyl substituted polyester was provided by dynamic rheological experiments. Based on thermogravimetric analysis, it was concluded that the thermal stability was affected only when four methyl side groups were present in the spacer. (C) 1995 John Wiley \& Sons, Inc.

Keywords: butanediol $\bullet 4,4$ '-biphenyldicarboxylic acid $\bullet$ characterization $\bullet$ liquid crystalline polymer $\bullet$ methyl substitution $\bullet$ nematic $\bullet$ polyester $\bullet$ smectic $\bullet$ synthesis $\bullet$ thermal properties - X-ray analysis
\end{abstract}

\section{INTRODUCTION}

Although polyesters based on 4,4'-biphenyldicarboxylic acid and aliphatic diols have been known for several decades, ${ }^{1,2}$ their thermotropic liquid crystalline behavior has been reported only recently. ${ }^{3-10}$ The studies of these polyesters, designated as $\mathrm{BB} n$ with $n$ as the number of methylene groups in the diol, were mainly focused on the relationship between the smectic mesophase behavior and the number of methylene groups in the diol.

Since polyesters based on the nonmesomorphic

* To whom all correspondence should be addressed. Journal of Polymer Science: Part A: Polymer Chemistry, Vol. 33, 493-504 (1995) (c) 1995 John Wiley \& Sons, Inc. diethyl 4,4'-biphenyldicarboxylate and various alkanediols exhibit a smectic mesophase on melting, the structure of the alkanediol spacer apparently results in polymer chain conformations, which fit into the smectic mesophase type. The spacer's influence is also illustrated by the odd/even oscillation of the transition temperatures and the isotropization entropy with the number of intervening methylene units, $n^{6}$. The values of the transition temperatures and isotropization entropies are for polymers with an even number of methylene groups higher than for the neighboring polymers with odd numbered spacers. ${ }^{4,6}$

As the spacer length increases, the transition temperatures and the temperature regions of mesophase existence decrease. The latter effect indicates 
that the orientation of the 4,4'-biphenyldicarboxylate segment in the polymer chain becomes more random as the spacer length increases. The decreasing tendency for mesophase formation with increasing spacer length is illustrated by the thermal behavior of BB7, BB8, and BB9, which exhibit monotropic behavior, in which the mesophase is observed only upon cooling. ${ }^{4}$ In addition to the length of the spacer, other authors have shown that the thermotropic properties of polyesters based on $4,4^{\prime}$-biphenyldicarboxylic acid are also very sensitive to the chemical structure of the spacer such as the presence of oxygen atoms in the spacer backbone. ${ }^{7,9-13}$

From data given in literature on other thermotropic flexible polyesters, it appears that the structure of the spacer influences the type and/or the temperature range of stability of the mesophase ( $\mathrm{s}$ ) formed. ${ }^{14,15}$

It has been observed that the introduction of lateral methyl groups in (thermotropic) polyesters very effectively influences the thermal properties such as transition temperatures, mesophase texture, and crystallization behavior. ${ }^{1,2,16,17}$ However, little is known about this effect with respect to liquid crystalline polyesters based on 4,4'-biphenyldicarboxylic acid. The only information on the effect of methyl side groups in the spacer on the mesophase behavior of poly (4,4'-biphenyldicarboxylates) is given by Watanabe ${ }^{18}$ who found that the polyester prepared from 4,4'-biphenyldicarboxylic acid and the chiral 2-methyl-1,4-butanediol exhibits a chiral smectic $\mathrm{C}$ mesophase, whereas the unsubstituted 1,4-butanediol polyester has a smectic A mesophase.

The thermal properties of poly (alkylene 4,4'-biphenyldicarboxylates) have been reviewed by Goodman $^{1}$ and by Korshak and Vinogradova. ${ }^{2}$ The effect of one methyl side group in the spacer has been evaluated by using 1,2-propylene glycol, ${ }^{1,2} 1,3$ butanediol, ${ }^{2}$ and 2,2-dimethyltrimethylene glycol ${ }^{1,2}$ as a spacer, and comparing the results with those from the unsubstituted diols. Each of the substituted polyesters had a lower melting point than the unsubstituted one.

In this article, we will discuss the effect of methyl substituents in 1,4-butanediol in polyesters with 4,4'biphenyldicarboxylic acid on the liquid crystalline properties and the melting temperatures. Although methyl substitution will probably result in a decrease of the melting temperature, the formation of a nematic mesophase is of much more interest, because fibers with good mechanical properties are often obtained by melt processing in the nematic phase. Therefore, rheological properties of some of the polyesters have been studied that exhibit a nematic mesophase. The thermal stability of the polyesters was also investigated, in order to study to what extent the thermal stability is affected by the degree of methyl substitution on the spacer.

\section{EXPERIMENTAL}

\section{Materials}

4,4'-Biphenyldicarboxylic acid (Aldrich, 97\%), dimethyl methylsuccinate (Aldrich, 99\%), 2,2-dimethylsuccinic acid (Aldrich, 99\%), 2,3-dimethylsuccinic acid (Aldrich, 99\%, mixture of d,l, and meso), ethanol (Merck, p.a.), lithium aluminum hydride ( $\mathrm{LiAlH}_{4}$, Merck, z.S.), phenol (Merck, z.S.), 1,1,2,2-tetrachloroethane (Aldrich, 99\%), and titanium(IV) isopropoxide (Merck, z.S.) were used without further purification.

1,4-Butanediol (Merck, z.S) was distilled in the presence of $\mathrm{Na}_{2} \mathrm{SO}_{4}$ under reduced pressure prior to use. Dichloromethane $\left(\mathrm{CH}_{2} \mathrm{Cl}_{2}\right.$, Merck, z.S. $)$ and pyridine (Merck, z.S.) were distilled over $\mathrm{CaH}_{2}$ and stored under nitrogen. Toluene (Merck, z.S.) was distilled from sodium/benzophenone prior to use. Thionylchloride (Merck, z.S.) was distilled from triphenylphosphite (10 vol \%) prior to use.

\section{Monomer Synthesis}

\section{4,4'-Biphenyldicarbonyl Dichloride (1a)}

Monomer ( 1a) was prepared by a slightly modified procedure reported for the synthesis of azodibenzoyl chloride $^{19}$ : A solution of $100.96 \mathrm{~g}(0.417 \mathrm{~mol})$ of $4,4^{\prime}$ biphenyldicarboxylic acid in $774.7 \mathrm{~g}(6.51 \mathrm{~mol})$ of thionylchloride and $5 \mathrm{~mL} \mathrm{DMF}$ was refluxed for 24 h. Excess thionylchloride was distilled off and the crude reaction product was recrystallized from 800 $\mathrm{mL}$ dry toluene yielding $99.54 \mathrm{~g}(86 \%)$ pure diacid chloride: $\mathrm{mp} 184.5-186^{\circ} \mathrm{C}$.

\section{Diethyl 4,4'-Biphenyldicarboxylate (1b)}

Since no detailed synthesis was described in the literature, the following procedure was applied: 37.82 $\mathrm{g}(0.136 \mathrm{~mol})$ of $1 \mathrm{a}$ was added to an excess of ethanol $(1.03 \mathrm{~mol})$ in $250 \mathrm{~mL}$ pyridine at $0^{\circ} \mathrm{C}$. After stirring for $1 \mathrm{~h}$ at $60^{\circ} \mathrm{C}$, the product crystallized from solution upon cooling. Then, $500 \mathrm{~mL} \mathrm{CH}_{2} \mathrm{Cl}_{2}$ was added to the solution and subsequently the organic layer was washed with aq $\mathrm{Na}_{2} \mathrm{CO}_{3}$ and sat. aq $\mathrm{NaCl}$ and dried over $\mathrm{MgSO}_{4}$. Evaporation of the $\mathrm{CH}_{2} \mathrm{Cl}_{2}$ gave the crude product, which was recrystallized twice 
from $400 \mathrm{~mL}$ ethanol, yielding $34.24 \mathrm{~g}$ (85\%) of $1 \mathrm{~b}$; mp 113.5-114.5 ${ }^{\circ} \mathrm{C}$ (lit. ${ }^{20} \mathrm{mp} 111.5^{\circ} \mathrm{C}$ ). ${ }^{1} \mathrm{H}$ NMR $\left(\mathrm{CDCl}_{3}, \mathrm{TMS}\right): \delta=1.43\left(\mathrm{t}, 3 \mathrm{H},-\mathrm{CH}_{2} \mathrm{CH}_{3}\right)$, $4.42\left(\mathrm{q}, 2 \mathrm{H},-\mathrm{CH}_{2} \mathrm{CH}_{3}\right), 7.93-8.15(\mathrm{AB}, 8 \mathrm{H}$, $\left.-\mathrm{C}_{6} \mathrm{H}_{4}-\right)$.

The methyl substituted 1,4-butanediols 3b-3f were prepared by reduction of the corresponding succinic esters with lithium aluminum hydride in diethylether ${ }^{21}$ (Fig. 1). The diols $\mathbf{3 b}-\mathbf{3 d}$ were purified by distillation, whereas $3 \mathbf{f}$ was recrystallized from petroleumether $40-60 /$ diisopropylether (95/ $5 \mathrm{v} / \mathrm{v}) .^{22}$ The succinic ester $2 \mathrm{~b}$ was commercially available, $2 \mathrm{c}$ and $\mathbf{2 d}$ were synthesized from the corresponding succinic acids by a procedure for the esterification of dicarboxylic acids, ${ }^{23}$ whereas $2 \mathbf{e}$ and 2f were prepared according to a procedure of Petragnani et al. ${ }^{24}$

\section{2,2,3-Trimethyl-1,4-butanediol (3e)}

The synthesis of $3 \mathbf{e}$ has not been reported previously. The compound was prepared by reduction of dimethyl-2,2,3-trimethylsuccinate with lithium aluminum hydride in diethylether according to the procedure described for the diols 3b-3f. The diol 3e was isolated by distillation giving a colorless viscous liquid, which partially crystallized on standing: yield $57 \%$, bp $87-90^{\circ} \mathrm{C}$ (0.03 mbar). According to $\mathrm{GC}$, the diol was contaminated with other products, which remained present after several distillations (purity $=92.5 \%) \cdot{ }^{1} \mathrm{H} \mathrm{NMR}\left(\mathrm{CDCl}_{3}, \mathrm{TMS}\right): \delta=0.82$ (s, $\left.6 \mathrm{H},-\mathrm{C}\left(\mathrm{CH}_{3}\right)_{2}-\right), 0.93\left(\mathrm{~d}, 3 \mathrm{H},-\mathrm{CH}\left(\mathrm{CH}_{3}\right)-\right)$,

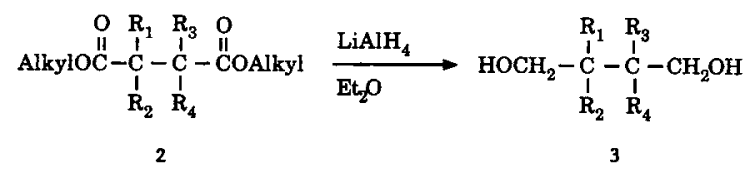

\begin{tabular}{|c|c|c|c|c|c|c|c|}
\hline $\mathrm{R}_{1}$ & $\mathbf{R}_{2}$ & $\mathrm{R}_{3}$ & $\mathbf{R}_{\mathbf{4}}$ & & & & \\
\hline $\mathrm{H}$ & $\mathrm{H}$ & $\mathbf{H}$ & $\mathbf{H}$ & $2 a$ & $3 a$ & $2 a$ & $3 a$ \\
\hline $\mathrm{CH}_{3}$ & $\mathbf{H}$ & $\mathbf{H}$ & $\mathbf{H}$ & $2 b$ & $3 b^{23,41}$ & $2 b$ & $3 b^{21,36}$ \\
\hline $\mathrm{CH}_{3}$ & $\mathrm{CH}_{3}$ & $\mathbf{H}$ & $\mathbf{H}$ & $2 c^{25,27}$ & $3 c^{23,27}$ & $2 c^{23,37}$ & $3 c^{21,37}$ \\
\hline $\mathrm{CH}_{3}$ & $\mathbf{H}$ & $\mathrm{CH}_{3}$ & $\mathbf{H}$ & $2 d^{25,28}$ & $3 d^{23}$ & $2 d^{23,31}$ & $3 d^{21}$ \\
\hline $\mathrm{CH}_{3}$ & $\mathrm{CH}_{3}$ & $\mathrm{CH}_{3}$ & $\mathbf{H}$ & $2 e^{26}$ & $3 e$ & $2 c^{24}$ & $3 \mathbf{e}$ \\
\hline $\mathrm{CH}_{3}$ & $\mathrm{CH}_{3}$ & $\mathrm{CH}_{3}$ & $\mathrm{CH}_{3}$ & $2 \mathrm{f}^{22,29}$ & $3 \mathbf{f}^{23,24,29}$ & $2 f^{24,38}$ & $3 \mathrm{f}^{21,22,38}$ \\
\hline
\end{tabular}

Figure 1. Synthesis and structure of methyl substituted 1,4-butanediols. $0.97(\mathrm{~s}, ?), 1.41\left(\mathrm{~m}, 1 \mathrm{H},-\mathrm{CH}\left(\mathrm{CH}_{3}\right)-\right), 3.21$ (d, ?), 3.33-3.66 ( $\mathrm{m}, 4 \mathrm{H},-\mathrm{CH}_{2}-$ ), 3.97 [s (broad), $2 \mathrm{H}, \mathrm{OH}$.

\section{Polymer Synthesis}

Polymers were synthesized by transesterification of the diethyl ester of $4,4^{\prime}$-biphenyldicarboxylic acid and the appropriate diol, using isopropyl titanate as catalyst according to a slightly modified procedure as described by Jackson et al. ${ }^{25}$ The polymerization reaction was performed in a reaction setup as described by Auman et al. ${ }^{26}$ using a high torque mechanical stirrer. To a thick walled test tube equipped with a 29 / 32 ground glass joint were added $0.02 \mathrm{~mol}$ diethyl 4,4'-biphenyldicarboxylate and $0.047 \mathrm{~mol}$ diol. The tube was then fitted to a $29 / 32$ ground adapter equipped with a nitrogen inlet, a Liebigcondenser and a mechanical stirrer. A bent distilling adapter with a nitrogen/vacuum connection and a receiving flask was fitted to the condenser. The metal stir-rod was designed with a paddle blade so as to fit just inside the tube in order to provide good stirring throughout the melt. The polymerization setup was flushed with nitrogen after a vacuum was pulled on the system. This was done 3 times. The catalyst ( $100 \mathrm{ppm}$ titanium) was added as a $6 \mathrm{wt} \%$ solution in toluene by means of a syringe. The tube was inserted in a Wood's metal bath at $100-120^{\circ} \mathrm{C}$. After the content had melted, stirring was begun and the bath temperature was raised to $150^{\circ} \mathrm{C}$, and finally to $220^{\circ} \mathrm{C}$. While keeping the system under a slow nitrogen flow, heating and stirring were continued for 3-5 h until the ethanol flux had substantially subsided. The tube was next heated to $230-240^{\circ} \mathrm{C}$ for $30 \mathrm{~min}$. A vacuum was slowly pulled on the system and the reduced pressure was held below 0.4 mbar while heating and stirring continued for 3-5 $h$. While distilling off the excess diol, the viscosity was increasing. After the polycondensation was completed, the system was cooled and the polymer was isolated by dissolving in $60 / 40(\mathrm{w} / \mathrm{w})$ phenol/ tetrachloroethane and precipitating in excess methanol. The polymer was collected by filtration, washed with methanol, and dried in vacuo at $80^{\circ} \mathrm{C}$ for $24 \mathrm{~h}$.

\footnotetext{
Methods

${ }^{1} \mathrm{H}$ NMR spectra were recorded on a Bruker AC 250 spectrophotometer by using $\mathrm{CF}_{3} \mathrm{COOD}$ or $\mathrm{CDCl}_{3}$ as solvent. Inherent viscosities were determined at $25^{\circ} \mathrm{C}$ in phenol/tetrachloroethane $(60 / 40 \mathrm{w} / \mathrm{w})$ using an Ubbelohde viscometer at a polymer con-
} 


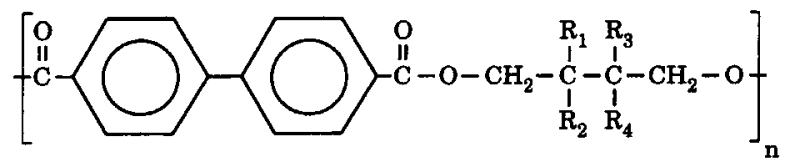

Figure 2. Chemical structure of the repeating unit of polyesters $4 \mathbf{a}-\mathbf{f}$.

centration of $0.25 \mathrm{~g} / \mathrm{dL}$. The thermal transitions were measured with a Perkin-Elmer DSC-7 differential scanning calorimeter equipped with a PE-7700 computer using TAS-7 software. The temperatures corresponding with the maximum values of the peaks were taken as the phase transitions, which were measured at a heating/cooling rate of $10^{\circ} \mathrm{C} /$ min. Optical polarization microscopy studies were carried out using a Leitz Ortholux II Pol BK microscope, equipped with a Mettler FP 82 hot stage and a Mettler FP 80 Control Processor. Photomicrographs were taken at an original magnification of 250x using a Leitz photo attachment. Melt viscosities were determined with a Rheometrics Mechanical Spectrometer Model RMS 800 using the parallel plate geometry. The measurements were made after $8 \mathrm{~min}$ at the given temperature. Thermogravimetric analysis was performed on a Perkin-Elmer TGA 7 Thermogravimetric Analyzer. The samples were run under a helium atmosphere with a flow rate of 2.0 $\mathrm{L} / \mathrm{h}$. Heating rates were $20^{\circ} \mathrm{C} / \mathrm{min}$ and $1.5-7.5 \mathrm{mg}$ of samples were used. Wide-angle $\mathrm{X}$-ray diffractograms in the $2 \theta$ range from $13-33^{\circ}$ were obtained using Ni-filtered $\mathrm{CuK}_{\alpha}$ radiation. Temperature-dependent diffractograms were taken from a circular film with a radius of $10 \mathrm{~mm}$ and a thickness of 0.5 $1.0 \mathrm{~mm}$, using a Guinier-Simon camera. Prior to the measurement, the sample was heated at a rate of $5^{\circ} \mathrm{C} / \mathrm{min}$ to the required temperature, followed by annealing for $30 \mathrm{~min}$. The sample temperature could be maintained within $\pm 2^{\circ} \mathrm{C}$ and was controlled by means of a thermocouple introduced into the nozzle in the direct vicinity of the specimen. Exposure times were approximately $3 \mathrm{~h}$. Optical density data were collected from the photographically obtained patterns using a linear microdensitometer LS20 (Delft Instruments) controlled by SCANPI software.

\section{RESULTS AND DISCUSSION}

\section{Polymer Synthesis}

The general structure of the polyesters prepared by melt transesterification of diethyl $4,4^{\prime}$-biphenyldi- carboxylate and the appropriate diol is presented in Figure 2. Table I shows data about the synthesis and viscosity of the polyesters. Polyester $4 a$ did not completely dissolve in the phenol/tetrachloroethane mixture. The polyesters $4 b, 4 c, 4 d$, and 5 precipitated as fibrous materials, and the inherent viscosity of some of these suggest a high molecular weight. Despite the low purity of diol 3e $(92.5 \%)$, a viscous melt of polyester $4 \mathrm{e}$ was formed. As with polyester $4 a$, the viscosities of $4 e$ and $4 f$ could not be measured because these polymers dissolved only partially in the phenol/tetrachloroethane mixture.

Copolyester 5 was prepared using equimolar amounts of $3 \mathbf{a}$ and $3 \mathbf{f}$. The composition was determined from its ${ }^{1} \mathrm{H}$ NMR spectrum, and it was found that the copolymer was enriched with $3 \mathrm{a}$ relative to $3 f$. The molar ratio of $3 a$ and $3 f$ in the copolyester was $72 / 28$. This effect has also been reported for the synthesis of copolyterephthalates based on ethylene glycol and various 2,3-dialkyl-1,4-butanediols. ${ }^{27}$ It was also found that, during the polymerization, dehydration and cyclization of the disubstituted butanediols to 2,3-dialkyltetrahydrofurans had occurred. In our case, apart from a possible difference in diol reactivity, this side reaction might explain the effect mentioned previously, because the presence of tetramethyltetrahydrofuran was indeed observed in the ${ }^{1} \mathrm{H}$ NMR spectrum of the polymerization distillate.

\section{Thermal Analysis}

Table II shows the effect of the diol component on the thermal properties of polyesters $4 a-f$ and copolymer 5 . The values of the transition temperatures, determined by DSC, refer to the temperatures

Table I. Polyesters from Diethyl

4,4'-Biphenyldicarboxylate and Methyl Substituted 1,4-Butanediols

\begin{tabular}{|c|c|c|c|c|c|c|}
\hline Polymer & $\mathrm{R}_{1}$ & $\mathrm{R}_{2}$ & $\mathbf{R}_{\mathbf{3}}$ & $\mathbf{R}_{4}$ & $\begin{array}{c}\text { Yield } \\
(\%)\end{array}$ & $\begin{array}{c}\eta_{\text {inh }} \\
(\mathrm{dL} / \mathrm{g})\end{array}$ \\
\hline $4 a$ & $\mathrm{H}$ & $\mathbf{H}$ & $\mathrm{H}$ & $\mathrm{H}$ & 80 & $-{ }^{a}$ \\
\hline $\mathbf{4} b^{b}$ & $\mathrm{CH}_{3}$ & $\mathbf{H}$ & $\mathrm{H}$ & $\mathrm{H}$ & 91 & 1.11 \\
\hline $4 \mathrm{c}$ & $\mathrm{CH}_{3}$ & $\mathrm{CH}_{3}$ & $\mathrm{H}$ & $\mathrm{H}$ & 84 & 0.46 \\
\hline $4 d^{c}$ & $\mathrm{CH}_{3}$ & $\mathbf{H}$ & $\mathrm{CH}_{3}$ & $\mathrm{H}$ & 80 & 0.35 \\
\hline $4 e^{b}$ & $\mathrm{CH}_{3}$ & $\mathrm{CH}_{3}$ & $\mathrm{CH}_{3}$ & $\mathbf{H}$ & 69 & $-{ }^{a}$ \\
\hline $4 f$ & $\mathrm{CH}_{3}$ & $\mathrm{CH}_{3}$ & $\mathrm{CH}_{3}$ & $\mathrm{CH}_{3}$ & 80 & $-{ }^{a}$ \\
\hline $\mathbf{5}$ & \multicolumn{4}{|c|}{ 3a/3f copolymer ${ }^{d}$} & 97 & 1.55 \\
\hline
\end{tabular}

Insoluble.

b Racemic mixture of enantiomers.

c Mixture of racemic diastereomers.

d $\mathbf{3 a} / \mathbf{3 f}$ molar ratio $=72 / 28$. 
Table II. Transition Temperatures and Thermodynamic Parameters of Polyesters 4a-f and Copolymer 5

\begin{tabular}{|c|c|c|c|c|c|c|}
\hline Polymer & $T_{m}\left({ }^{\circ} \mathrm{C}\right)$ & $\begin{array}{c}\mathrm{T}_{\mathrm{lc}-\mathrm{i}(\mathrm{i}-\mathrm{l} c)^{\mathrm{a}}} \\
\left({ }^{\circ} \mathrm{C}\right)\end{array}$ & $\begin{array}{c}\Delta H_{c}^{\mathrm{b}} \\
(\mathrm{kcal} / \mathrm{mol})\end{array}$ & $\begin{array}{c}\Delta S_{c}^{b} \\
(\mathrm{cal} / \mathrm{K} \cdot \mathrm{mol})\end{array}$ & $\begin{array}{c}\Delta H_{i}^{\mathrm{b}} \\
(\mathrm{kcal} / \mathrm{mol})\end{array}$ & $\begin{array}{c}\Delta S_{i}^{\mathrm{b}} \\
(\mathrm{cal} / \mathrm{K} \cdot \mathrm{mol})\end{array}$ \\
\hline \multirow[t]{2}{*}{$\mathbf{4 a}$} & 277 & 298 & & & & \\
\hline & $(240)$ & (289) & 0.99 & 1.95 & 0.97 & 1.75 \\
\hline \multirow[t]{2}{*}{$4 b$} & 217 & 237 & $0.79^{c}$ & $1.62^{\mathrm{c}}$ & $1.27^{\mathrm{c}}$ & $2.49^{c}$ \\
\hline & (163) & $(228)^{d}$ & 0.59 & 1.36 & 1.23 & 2.46 \\
\hline \multirow[t]{2}{*}{ 4c } & $174 / 183$ & - & & & & \\
\hline & $(137 / 145)$ & & 1.79 & 4.28 & - & - \\
\hline \multirow[t]{2}{*}{$4 d$} & $204 / 214$ & & & & & \\
\hline & (186) & - & 2.09 & 4.55 & - & - \\
\hline \multirow[t]{2}{*}{$4 e$} & 209 & & & & & \\
\hline & (168) & - & 2.40 & 5.33 & - & - \\
\hline \multirow[t]{2}{*}{$4 f$} & 277 & 290 & & & & \\
\hline & $(247)$ & (261) & 0.37 & 0.72 & 1.71 & 3.20 \\
\hline \multirow[t]{2}{*}{5} & $-^{e}$ & 280 & & & & \\
\hline & (184) & (265) & 0.29 & 0.62 & 1.65 & 3.07 \\
\hline
\end{tabular}

a lc-i: liquid crystalline-isotropic transition.

${ }^{\mathrm{b}}$ Crystallization enthalpy $\left(\Delta H_{c}\right)$, crystallization entropy $\left(\Delta S_{c}\right)$, isotropization enthalpy $\left(\Delta H_{i}\right)$, and isotropization entropy $\left(\Delta S_{i}\right)$ are based on cooling data.

${ }^{c} \Delta H_{c}, \Delta S_{c}, \Delta H_{i}$, and $\Delta S_{i}$ are based on heating data.

${ }^{\mathrm{d}}$ An intermediate transition was observed at $190^{\circ} \mathrm{C}$ with $\Delta H=0.21 \mathrm{kcal} / \mathrm{mol}$ and $\Delta S=0.45 \mathrm{cal} / \mathrm{K} \cdot \mathrm{mol}$.

${ }^{e}$ Not detectable in the DSC heating curve.

that correspond with the peak values of the successive endotherms observed upon a second heating of the sample at $10^{\circ} \mathrm{C} / \mathrm{min}$, while values given in parentheses refer to the corresponding exotherms when the sample was cooled a second time from the isotropic melt at $10^{\circ} \mathrm{C} / \mathrm{min}$. The DSC curves for the polyesters are shown in Figure 3 . The enthalpy and entropy values were calculated from the first exothermic transition on cooling from the isotropic melt.

As was already shown by Meurisse et al. ${ }^{3}$ and Krigbaum et al., ${ }^{4}$ polyester $4 \mathrm{a}$ exhibits a smectic $\mathrm{A}$ mesophase, which is characterized by the well-developed focal-conic texture presented in Figures 4 (a) and 4(b) and supported by the DSC thermogram in Figure 3. The isotropization enthalpy $\left(\Delta H_{i}\right.$ $=0.97 \mathrm{kcal} / \mathrm{mol}$ ), determined from the cooling scan, is rather low for an isotropic-smectic transition. ${ }^{28}$ According to Krigbaum et al., ${ }^{5}$ polyester $4 \mathrm{a}$ [BB4, $\eta_{\text {inh }}=0.28 \mathrm{dL} / \mathrm{g}(\mathrm{c}=0.5 \mathrm{~g} / \mathrm{dL}$, phenol $/$ tetrachloroethane $60 / 40$ )] has melting and isotropization temperatures of $273^{\circ} \mathrm{C}$ and $296^{\circ} \mathrm{C}$, respectively, with corresponding enthalpy values of 1.05 and $1.65 \mathrm{kcal} /$ mol repeating unit, respectively. From these data, the entropy of melting and isotropization were calculated as $1.92 \mathrm{cal} / \mathrm{K} \cdot \mathrm{mol}$ and $2.90 \mathrm{cal} / \mathrm{K} \cdot \mathrm{mol}$ repeating unit, respectively. According to Watanabe et al., ${ }^{6}$ the isotropic-liquid crystal transition temperature of the $\mathrm{BB} 4$ polyester was $298^{\circ} \mathrm{C}$, which in- dicates a higher molecular weight than the BB4 polyester of Krigbaum et al. ${ }^{5}$ The corresponding enthalpy and entropy values were $1.87 \mathrm{kcal} / \mathrm{mol}$ and $3.30 \mathrm{cal} / \mathrm{K} \cdot \mathrm{mol}$ repeating unit, respectively. ${ }^{6}$ Therefore, these values are taken as reference values in the discussion of the methyl side-group effect.

The effect of substituting one methyl group in the 1,4-butanediol unit ( $3 \mathbf{a}$ ) on the thermal behavior of the polyesters is evident, as can be seen by comparing the properties of $4 \mathbf{b}$ with those of $4 a$. The same reduction in transition temperatures has also been observed for the liquid-crystalline polyester, based on the mesogenic trans-4,4'-stilbenedicarboxylic acid ${ }^{25}$ and the diols $\mathbf{3 a}$ and $\mathbf{3 b}$ and is possibly related to the random arrangement of the asymmetric diols along the polymer backbone (copolymer effect). The asymmetric structure of $(R, S)-2$ methyl-1,4-butanediol (3b) can give rise to two randomization effects in a similar way as has been suggested by Doak et al. ${ }^{29}$ to explain the influence of methyl substituents on the melting points of linear aliphatic polyesters. As we are dealing with a racemic mixture of diols, the two stereo-isomers can arrange randomly along the polymer backbone. Next to this, the stereo-isomers can adopt a head-to-head, a head-to-tail, or a tail-to-tail arrangement with respect to each other.

In $4 \mathbf{b}$, the smectic $A$ mesophase texture of the unsubstituted polyester $\mathbf{4 a}$ has been replaced by a 


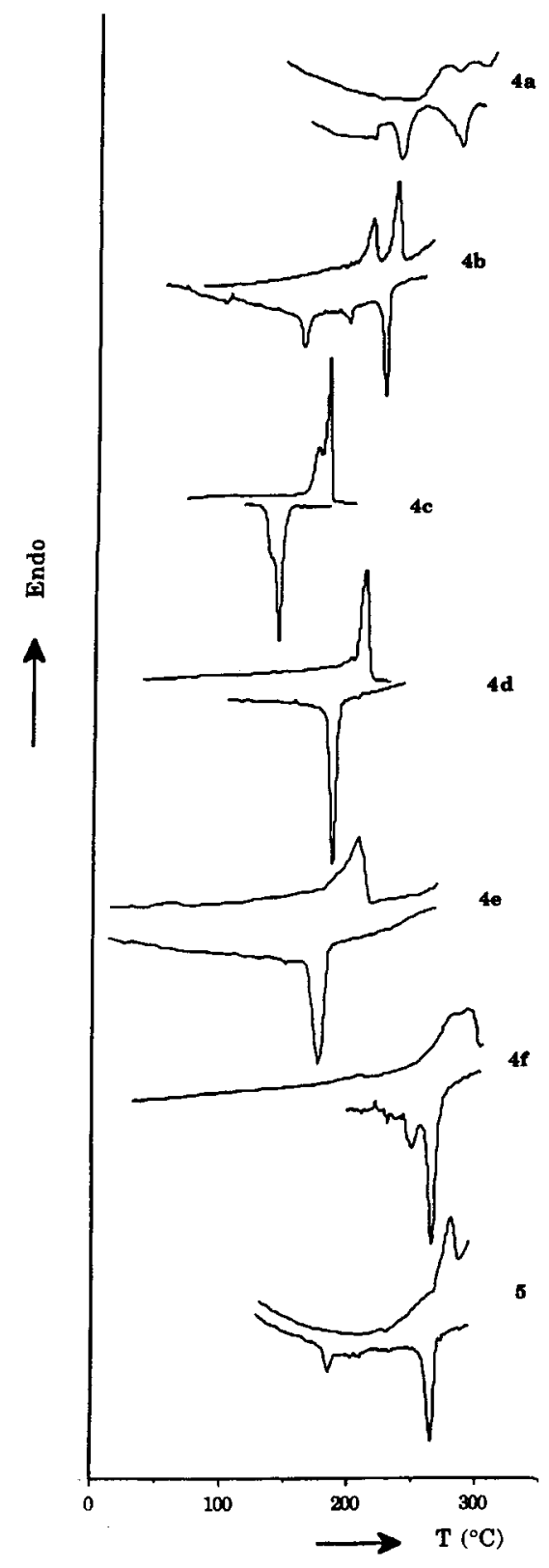

Figure 3. DSC thermograms of polyesters $4 a-f$ and copolymer 5 from the second heating and second cooling scans.

nematic type as shown in Figure 4(d). The formation of a nematic mesophase at the expense of the higher ordered smectic mesophase has also been observed for thermotropic polyesters based on $p$ terphenyl-4,4"-dicarboxylic acid and ethanediol or 1,5-pentanediol by substitution of methyl groups on C-1, C-1 and C-2 of ethanediol, and on C-3 of 1,5pentanediol, respectively. ${ }^{15}$ On the other hand, methyl groups on C-1 of 1,3-propanediol or 1,4-bu- tanediol have been reported to favor the thermal stability of smectic mesophases of the corresponding liquid crystalline polyesters based on $4,4^{\prime}$ - (terephthaloyldioxy) dibenzoic acid. ${ }^{14}$

It is interesting to note that poly ( $4,4^{\prime}$-biphenyldicarboxylate) based on optically pure 2-methyl-1,4butanediol has been reported to exhibit a chiral smectic C mesophase. ${ }^{18}$ However, no data on the transition temperatures were given. The DSC cooling curve of $\mathbf{4 b}$ shows an additional exotherm at $199^{\circ} \mathrm{C}$, suggesting the presence of a second mesophase of higher symmetry below this temperature. However, this could not be confirmed by polarization microscopy as can be seen from Figures 4(c) and $4(d)$.

From the heating curve of polyester $4 b$, the entropy of melting and isotropization have been calculated to be $1.62 \mathrm{cal} / \mathrm{K} \cdot \mathrm{mol}$ and $2.49 \mathrm{cal} / \mathrm{K} \cdot \mathrm{mol}$, respectively. These values are consistent with the theory of a rodlike structure of the molecules in the nematic mesophase according to which the isotropization entropy must be larger than the melting entropy. However, as the crystallinity is less than $100 \%$ (semi-crystalline material), the real value of the entropy of melting is probably much larger.

From the heating curve of polyester $\mathbf{4 b}$, the isotropization enthalpy appears to be $1.27 \mathrm{kcal} / \mathrm{mol}$. This is a rather high value for a nematic-isotropic transition, normally $\Delta H_{i}=0.30-0.85 \mathrm{kcal} / \mathrm{mol}^{28}$ However, the enthalpy change of the isotropicmesophase transition $\left(\Delta H_{i}=1.23 \mathrm{kcal} / \mathrm{mol}\right)$ is lower than the corresponding value for the unsubstituted polyester $4 \mathrm{a}\left(\Delta H_{i}=1.87 \mathrm{kcal} / \mathrm{mol}^{6}\right)$, which has a smectic A mesophase. Therefore, the mesophase has a lower degree of organization and, thus, is probably of the nematic type. Additional evidence for the isotropic-nematic transition is given by the formation of nematic droplets, which could be observed on cooling from the isotropic phase.

As was expected, because of the difference in degree of order between the smectic and nematic mesophase, the isotropization entropy of $4 \mathrm{~b}\left(\Delta S_{i}\right.$ $=2.46 \mathrm{cal} / \mathrm{K} \cdot \mathrm{mol}$ ) is smaller than the value for the unsubstituted analogue as given by Watanabe et al. ${ }^{6}$ $\left(\Delta S_{i}=3.30 \mathrm{cal} / \mathrm{K} \cdot \mathrm{mol}\right)$ though the difference is not as large as one would expect considering both degrees of ordering.

The melting behavior of polyester $4 c$ is quite different from that of $\mathbf{4 b}$. Although no evidence could be obtained for mesophase textures by means of polarization microscopy, the multiple endo-and exotherms of the DSC thermogram in Figure 3 give rise to doubts concerning this point. In this thermogram, 


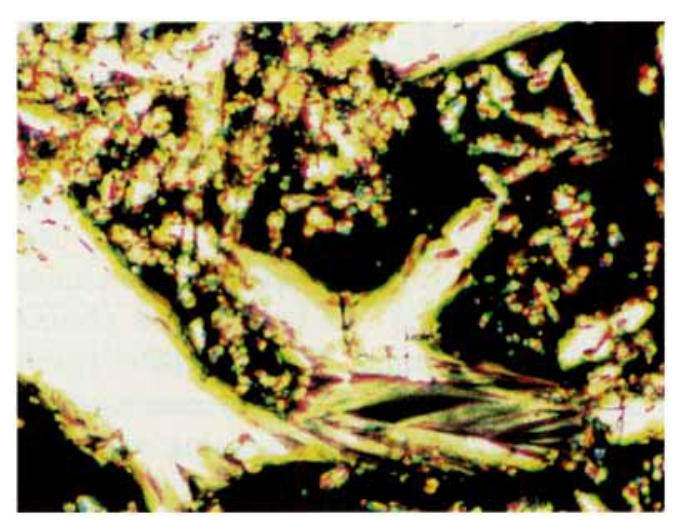

(a)

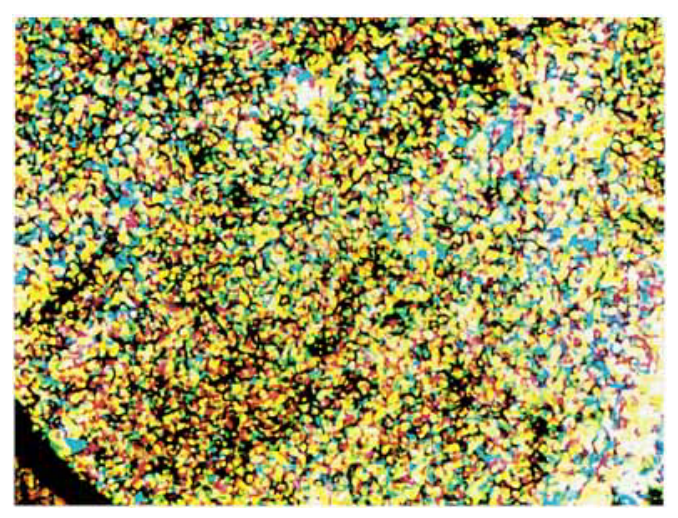

(c)

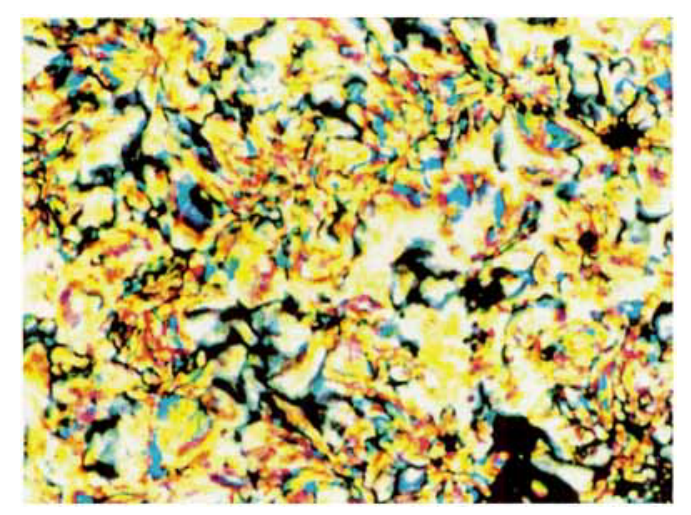

(e)

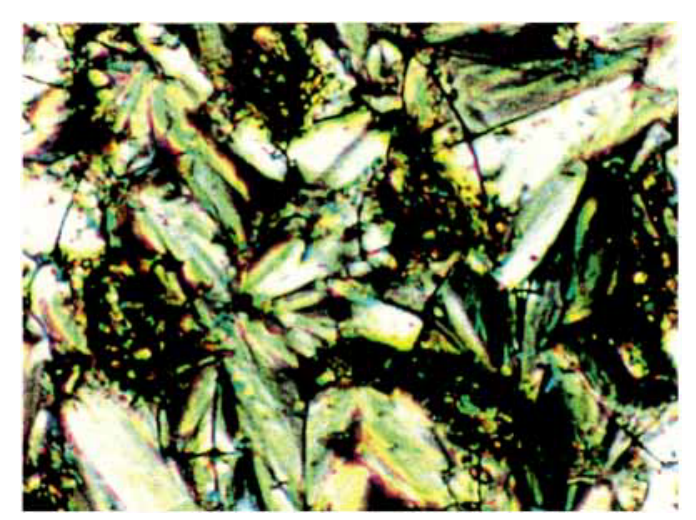

(b)

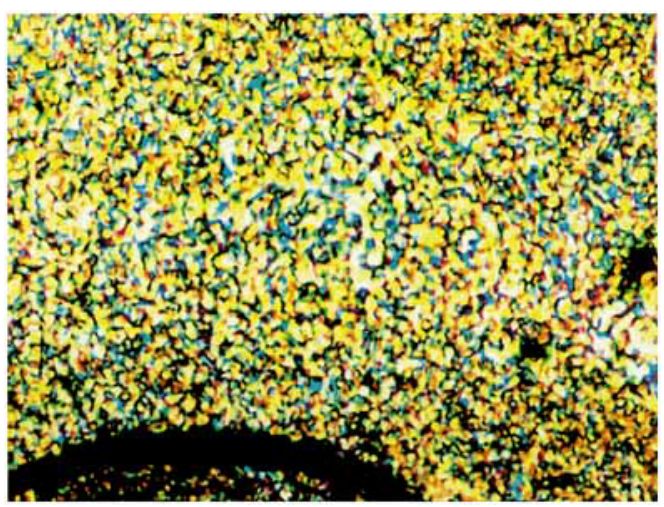

(d)

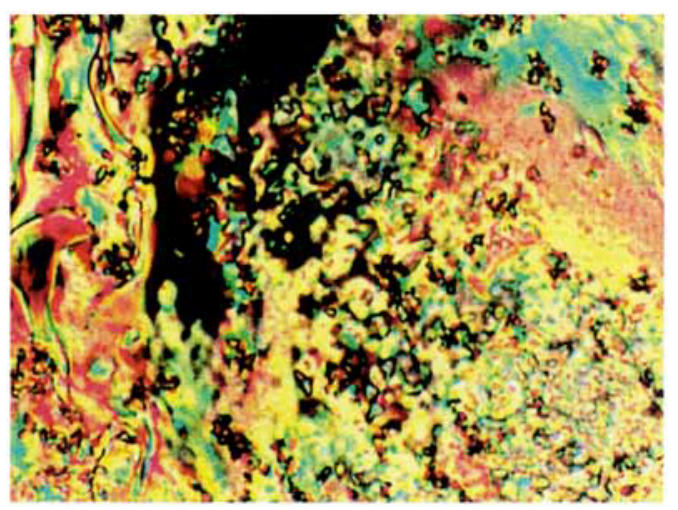

(f)

Figure 4. Representative optical polarized micrographs of polyesters $4 a, 4 b, 4 f$, and copolymer 5 (magnification $250 \times$ ). The photographs are reduced to $75 \%$ of the original size. (a) Formation of Batonnets upon coolong from isotropic melt of $4 \mathrm{a}$ at $284^{\circ} \mathrm{C}$. (b) Focal-conic structure of the smetic A mesophase of $4 \mathrm{a}$ at $260^{\circ} \mathrm{C}$ upon cooling from isotropic melt. (c) Mesophase of $4 \mathrm{~b}$ at $190^{\circ} \mathrm{C}$ upon cooling from the isotropic melt. (d) Mesophase of $4 \mathrm{~b}$ at $210^{\circ} \mathrm{C}$ upon cooling from the isotropic melt. (e) Mesophase of $4 \mathrm{f}$ at $275^{\circ} \mathrm{C}$. (f) Nematic texture of the mesophase of 5 at $250^{\circ} \mathrm{C}$ upon cooling from the isotropic melt. 


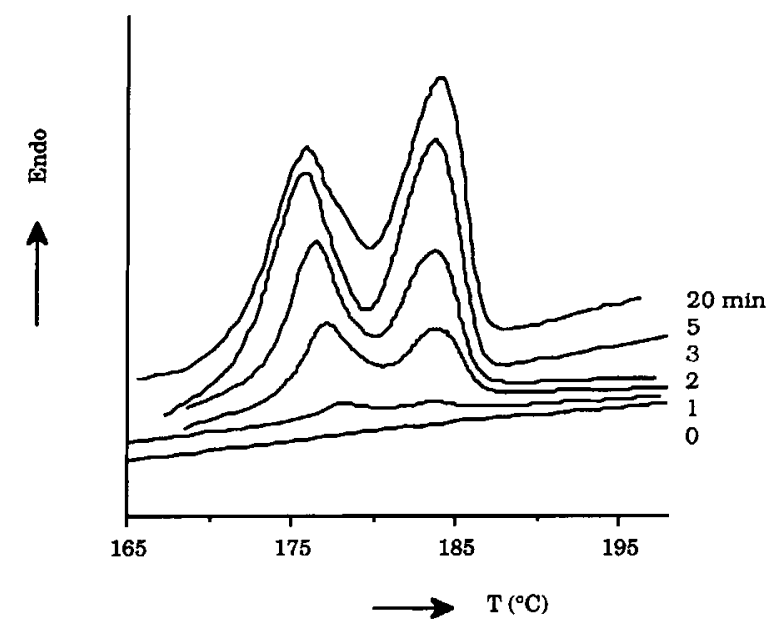

Figure 5. DSC heating curves of polyester 4c after isothermal crystallization at $170^{\circ} \mathrm{C}$, starting from the isotropic melt. The curves correspond to $0,1,2,3,5$, and 20 min of crystallization time, respectively, from bottom to top. Scanning rate was $10^{\circ} \mathrm{C} / \mathrm{min}$.

it can be seen that the first exothermic transition upon cooling from the isotropic melt occurs with a large undercooling effect, so it is unlikely that this exotherm corresponds to an isotropic-mesophase transition. Further, the endotherms were studied in more detail by annealing, after first cooling from the isotropic melt, at $170^{\circ} \mathrm{C}$ for certain periods of time and subsequently heating to above the melting point. Figure 5 shows that an endothermic transition at $174^{\circ} \mathrm{C}$ is developing faster than the transition at $183^{\circ} \mathrm{C}$. This result does not agree with the assumption that the two transitions represent a crystallinemesophase and a mesophase-isotropic transition, respectively. Hence, the endothermic transition of polyester $4 \mathrm{c}$ at $174^{\circ} \mathrm{C}$ probably should be assigned to a crystal-to-crystal transition in the solid state.

The heating and cooling curves of polyesters $4 d$ and $4 e$ show single endotherms and exotherms. A large undercooling was observed for the exotherms, too large for an isotropic-mesophase transition. In addition, observations from polarization microscopy did not indicate mesophase properties.

The heating and cooling curves of polyester $4 \mathrm{f}$ exhibit two overlapping endotherms and two separate exotherms, respectively. Although some birefringence was observed between the endotherms as shown by Figure 4(e), no clear evidence was obtained by means of polarization microscopy. No nematic droplets could be observed on cooling from the isotropic phase. In addition, the undercooling of both transitions appears to be of the same order and too large for an isotropic-mesophase transition.

\section{Dependence of $T_{m}$ on the Molecular Structure}

The melting temperature of a semi-crystalline polymer $\left(T_{m}=\Delta H_{m} / \Delta S_{m}\right)$ depends on intramolecular and intermolecular properties of the polymeric chains. The enthalpy of fusion $\left(\Delta H_{m}\right)$ is determined by the attraction forces between the chains and is, therefore, strongly related to the chain-packing ability of the polymer. The entropy of fusion $\left(\Delta S_{m}\right)$ is mainly determined by the symmetry and the spatial arrangement of the repeating units and by the polymer chain flexibility. ${ }^{1,2,30}$

It is known that melting point and crystallinity of polyesters can be decreased by introducing lateral methyl groups on the chain, which results in an less regular polymer structure and will decrease the melting enthalpy and increase the entropy of fusion. ${ }^{1}$ This effect can account for the lower melting point of polyester $\mathbf{4 b}$ compared to the higher melting unsubstituted analogue 4a. As mentioned previously, the irregularity is caused by the different sequences of the asymmetric diols in the polyesters and by the racemic character of the diol used.

The molecular structure of polyester $4 \mathbf{c}$ is less regular than that of $4 a$. Consequently, polyester $4 \mathbf{c}$ has a substantially lower melting point, which, apart from enthalpic differences, is probably due to a much higher entropy of fusion since the nonliquid crystalline polyester $4 \mathrm{c}$ melts to an isotropic melt.

The melting temperature of the nonliquid crystalline polyester $4 \mathbf{d}$ lies between the values of $\mathbf{4 b}$ and $4 \mathrm{c}$. Regarding the chirality of the diol used, there are three stereo-isomers ( $R, R, S, S$, and meso) present, which means that the irregularity of the chains in polyester $4 \mathbf{d}$ has increased. On the other hand, there is no head-to-head or head-to-tail effect because the diol is symmetric. Furthermore, the effect of an irregular structure on the entropy of fusion may be counteracted by a steric effect related to the presence of the two methyl groups on adjacent carbon atoms causing an increase in steric hindrance for rotation and thereby lowering the polymer chain flexibility. These effects do have an opposite effect on the entropy of fusion, thus making a reliable estimation of the effect of methyl side groups on the melting point very complicated. According to the literature, the effect of adjacent methyl groups in a diol spacer of a polyester can be either an increase ${ }^{14}$ or a decrease ${ }^{14,15,31}$ of the polymer melting point.

Polyester 4e has three methyl side groups, which should give rise to an increase in steric hindrance for rotation, thereby lowering the configurational entropy of the polymer. The structural irregularity of this polyester is similar to that of polyester $\mathbf{4 b}$. 
The structural irregularity of polyester $4 \mathbf{e}$ is caused by the different sequences of the asymmetric diols along the polymer backbone and also by the racemic character of the diol used. The melting point is lower than that of $\mathbf{4 b}$, whereas a higher value was expected considering the lower polymer chain flexibility. This may be explained by the melting entropy of polyester 4e, which is much larger, since it melts to an isotropic phase. It is even larger than the total sum of entropy changes of polyester $4 \mathrm{~b}(4.27 \mathrm{cal} / \mathrm{K} \cdot \mathrm{mol})$. However, the molecular weight of polyester $4 \mathbf{e}$ (considering that the purity of diol 3e was only $92.5 \%$ ) is probably too low for the properties to be molecular weight independent, so no significant conclusions can be drawn.

Polyester $4 \mathrm{f}$ has a substantially higher melting point than the lower substituted analogues. This can be accounted for by the symmetric structure of the repeating unit and the low polymer chain flexibility, both giving rise to a decrease of the melting entropy. Actually, based on the lower chain flexibility, we expected the melting point of $\mathbf{4 f}$ to be much higher than the unsubstituted analogue. But polyesters $4 \mathbf{a}$ and $4 f$ have the same melting point. Thus, there must be an effect compensating for the higher chain flexibility of polyester 4a. Possibly the packing ability of $\mathbf{4 a}$ chains is facilitated, when compared to the packing ability of $\mathbf{4 f}$ chains, causing a rise in the melting point.

The transition temperatures of polyester $4 \mathrm{f}$ are relatively high, which means that decomposition may take place during melt processing. Therefore, copolyester 5 was prepared from 4,4'-biphenyldicarboxylic acid and the diols $3 \mathbf{a}$ and $\mathbf{3 f}$ in order to obtain a lower melting polyester, which might also display mesomorphic properties. The DSC thermogram of copolyester 5 is shown in Figure 3 and seems to represent monotropic behavior at first sight. According to polarization microscopy, the copolyester starts melting between $230-240^{\circ} \mathrm{C}$ and exhibits a nematic mesophase as is shown in Figure 4 (f). Next to this, nematic droplets were clearly observed on cooling from the isotropic phase (at $255^{\circ} \mathrm{C}$ ). With respect to this observation, it is worthwhile to mention that Krigbaum et al. ${ }^{4}$ attempted to obtain nematogenic poly $\left(4,4^{\prime}\right.$-biphenyldicarboxylates), because polyesters that exhibit a nematic mesophase could be interesting materials because good mechanical properties are generally obtained when melt processing is performed in the nematic phase. ${ }^{8}$ They prepared copolyesters based on $4,4^{\prime}$-biphenyldicarboxylic acid, terephthalic acid, and ethylene glycol or hexanediol in order to disrupt the regular smectic phase of poly (alkylene $4,4^{\prime}$-biphenyldicarboxylates) and, thus, to obtain a nematic mesophase. However, no evidence was found for a nematic mesophase in any of the copolymers and the mesophases that could be identified were smectic. Jackson et al. ${ }^{8}$ prepared copolyesters based on 4,4'-biphenyldicarboxylic acid and a mixture of aliphatic diols, but they did not find evidence for nematic mesophases either.

\section{X-Ray Diffraction}

Polyester $4 \mathrm{~b}$ was examined by means of wide-angle $\mathrm{X}$-ray diffraction in order to elucidate the mesophase type and the nature of the intermediate transition in the cooling curve of the DSC thermogram in Figure 3. For this purpose, polyester $\mathbf{4 b}$ was first heated to the isotropic phase and subsequently cooled to room temperature at a cooling rate of $5^{\circ} \mathrm{C} / \mathrm{min}$. The diffractograms recorded at $210^{\circ} \mathrm{C}, 180^{\circ} \mathrm{C}$, and room temperature are presented in Figure 6.

The diffractogram recorded at $210^{\circ} \mathrm{C}$ shows two small reflections at $2 \theta=27.6^{\circ}$ and $2 \theta=29.2^{\circ}$, and

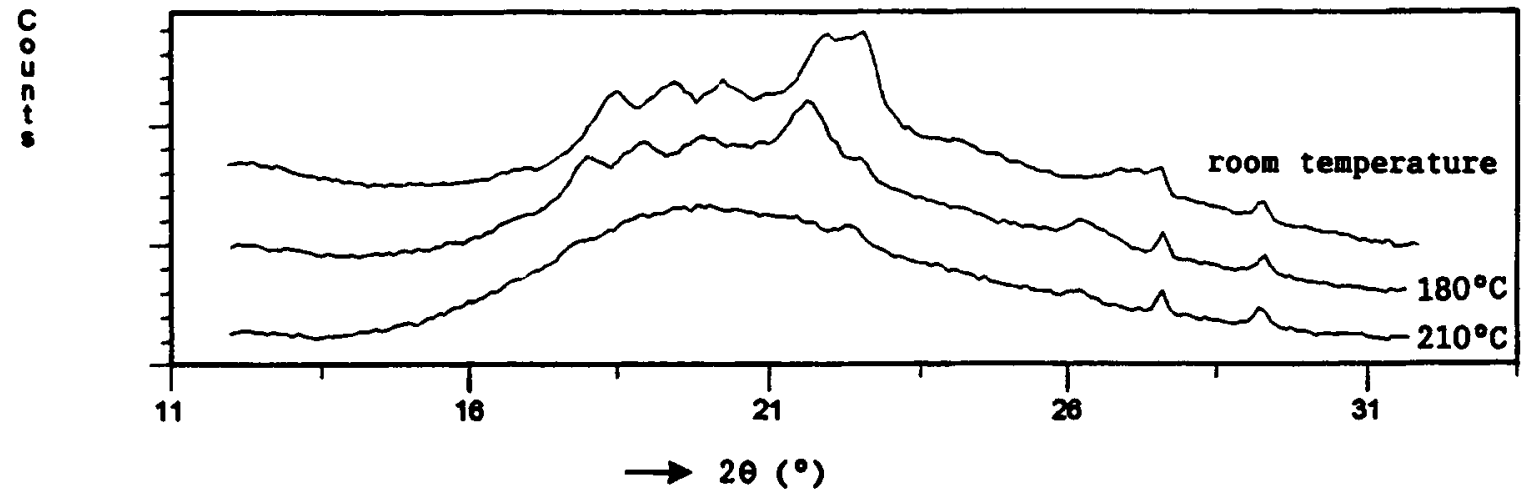

Figure 6. Temperature-dependent WAXD diffractograms of polyester $4 \mathbf{b}$. 
a broad peak between $16-26^{\circ}$, centered at $2 \theta=20^{\circ}$. The latter value corresponds to a Bragg spacing of $0.44 \mathrm{~nm}$, which is attributed to the average intermolecular distance. This value is in agreement with those reported in the literature for other poly (alkylene $4,4^{\prime}$-biphenyldicarboxylate) $\mathrm{s} .{ }^{9,11,16}$ In the $\mathrm{X}$-ray diffractogram recorded at $180^{\circ} \mathrm{C}$, additional reflections are present, superimposed onto the amorphous halo. A similar diffractogram was obtained at room temperature.

From the results, we can conclude that the broad peak in the diffractogram recorded at $210^{\circ} \mathrm{C}$ is associated with a nematic mesophase. This was already concluded from the polarization microscopy studies. Although the diffraction pattern recorded at $180^{\circ} \mathrm{C}$ exhibited additional reflections, which is indicative of a higher-ordered phase, no proper spacings could be calculated, because the peaks were rather small and broad. So, no conclusions could be drawn regarding the type of mesophase between $190-166^{\circ} \mathrm{C}$. From the diffractogram obtained at room temperature, it can be seen that polyester $\mathbf{4 b}$ is a low-crystalline material.

\section{Rheological Characterization}

Polyesters $4 \mathrm{~b}$ and 5 were studied by rheometric measurements in order to find further evidence for a nematic mesophase. Therefore, the shear rate dependency of the complex viscosity of these polymers in the mesophase and the isotropic phase was compared. The results of the rheological properties of polyesters $4 \mathbf{b}$ and 5 are shown in Figure 7 and it can be seen that, for polyester $4 \mathrm{~b}$ at $225^{\circ} \mathrm{C}$, the complex viscosity, $\eta^{*}$, was lower than at $270^{\circ} \mathrm{C}$ in the region of high frequency, $\omega$, whereas at low frequencies the opposite was observed. At $270^{\circ} \mathrm{C}$ the polyester exhibits an isotropic melt, while at $225^{\circ} \mathrm{C}$ (on cooling from the isotropic melt) the polyester displays a nematic mesophase. The curve at $270^{\circ} \mathrm{C}$ consists of a Newtonian plateau followed by a shear thinning region at higher frequencies, which is typical for isotropic melts of random-coil polymers. At $225^{\circ} \mathrm{C}$, a shear rate dependence of the complex viscosity is present in the whole frequency spectrum applied, increasing with the frequency. A similar behavior as observed for polyester $\mathbf{4 b}$ has been found with other thermotropic liquid-crystalline polyesters that exhibit both a nematic and an isotropic phase. ${ }^{32}$

As can be seen from Figure 7, copolyester 5 displays a rheological behavior similar to polyester $\mathbf{4 b}$. The complex viscosity of copolyester 5 at $305^{\circ} \mathrm{C}$ decreased significantly as the result of thermal degradation, so measurements were made after a shorter time ( $1 \mathrm{~min}$ instead of $8 \mathrm{~min}$ ). Thermal degradation

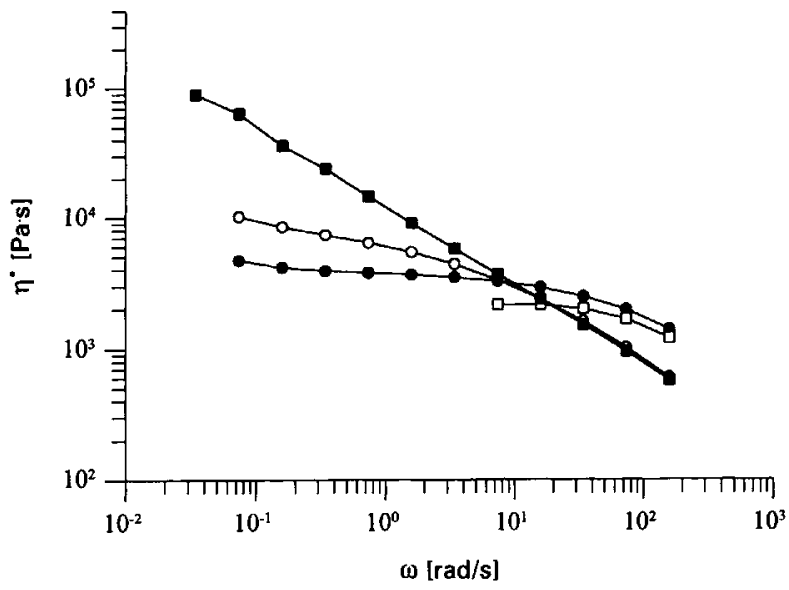

Figure 7. Complex viscosity as a function of frequency for polyester $4 \mathrm{~b}:(-\mathrm{O}-) 225^{\circ} \mathrm{C}$ and $(-0-) 270^{\circ} \mathrm{C}$; and copolymer $5(-\mathbf{-}) 260^{\circ} \mathrm{C}$ and $(-\square-) 305^{\circ} \mathrm{C}$.

was also occurring with polyester $4 \mathrm{~b}$ at $270^{\circ} \mathrm{C}$, though to a minor extent. Copolyester 5 exhibits a nearly constant shear-rate dependence of the complex viscosity in the mesophase with the values coinciding with those of polyester $4 \mathrm{~b}$ at high frequencies. The complex viscosity of copolyester $\mathbf{5}$ at low frequencies is much higher than that of polyester $4 \mathbf{b}$.

Apart from a possible molecular weight effect, it is suggested that the difference in low shear behavior exhibited by polyesters $4 \mathrm{~b}$ and 5 may be due to different polydomain structures, each with a different yield stress value. ${ }^{33}$ Also, the different mesophase textures, which were observed by means of polarization microscopy, may support this suggestion.

\section{Thermal Stability}

The thermal stability of polyesters $4 a-f$ was evaluated by means of TGA measurements carried out under helium. The results are shown in Figures 8(a) and $8(\mathrm{~b})$ and it can be seen that for polyesters $4 a-d$ thermal degradation is occurring at $300^{\circ} \mathrm{C}$. The degradation curves are of the same form, although for $4 a$ the first derivative of the TGA curve shows a less continuous path. Obviously, the thermal stability is not significantly affected up to two methyl side groups on the spacer. The onset of thermal degradation of the higher substituted analogues $4 e$ and 4f appeared to be at lower temperatures. However, in case of $4 \mathbf{f}$, the temperature of maximum degradation rate is higher $\left(449^{\circ} \mathrm{C}\right)$ than for all the other corresponding values.

The higher thermal stability of $\mathbf{4 f}$ may be due to the absence of $\beta$ hydrogen atoms in the polyester backbone, which are essential for the degradation 


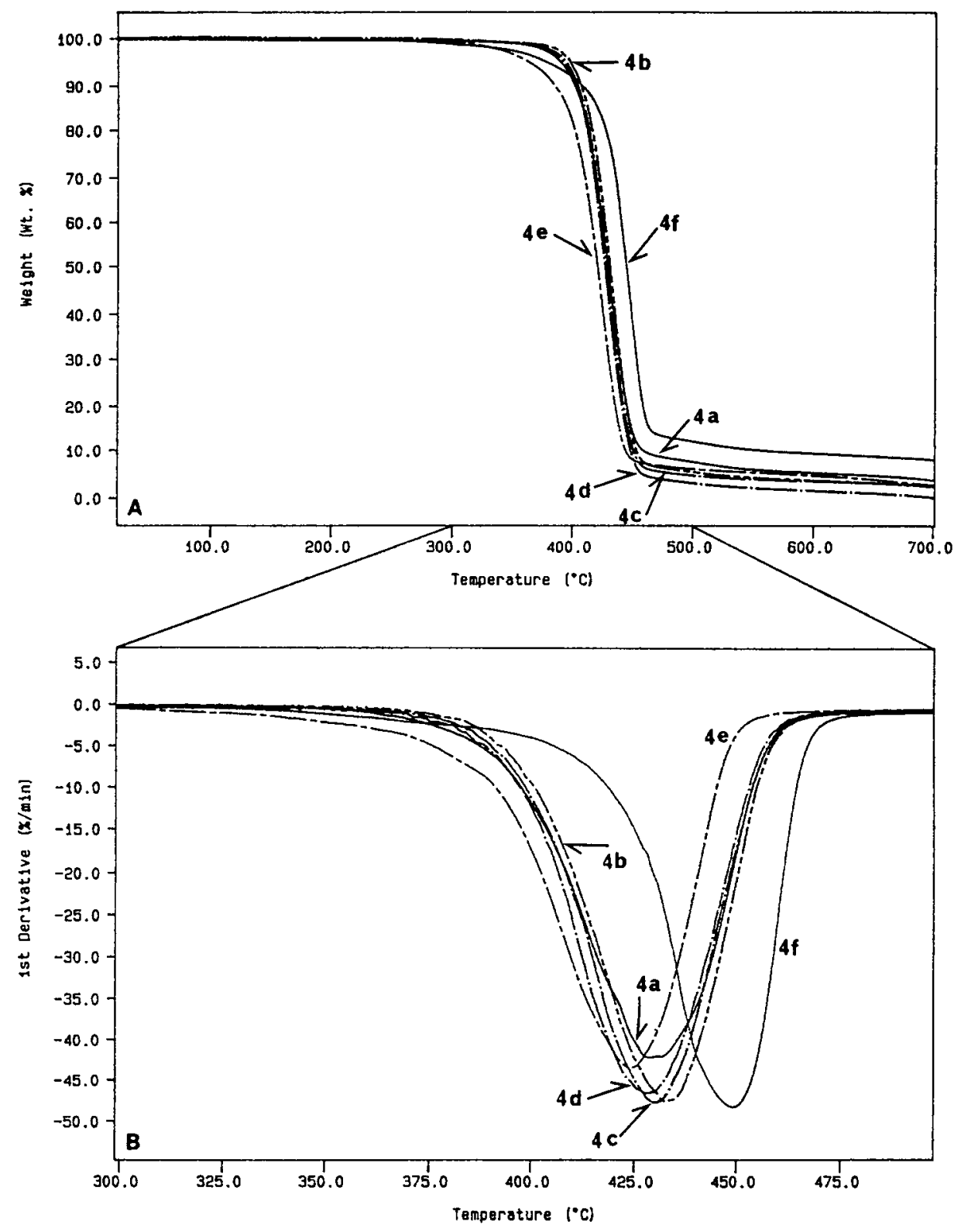

Figure 8. TGA of polyesters $4 a-f$.

mechanism occurring through concerted reactions involving a 6 -membered transition state. This mechanism is responsible for thermal degradation of poly (ethylene terephthalate) and poly (butylene terephthalate). ${ }^{34}$ Thermal degradation of $\mathbf{4 f}$ may occur through another mechanism in which $\alpha$ hydrogen transfer takes place and is known to occur at higher temperatures. ${ }^{35}$

\section{CONCLUSIONS}

Upon substituting methyl groups on the C-2 and/ or C-3 position of the 1,4-butanediol spacer of the liquid crystalline poly (butylene $4,4^{\prime}$-biphenyldicarboxylate), the melting points were decreased, except for the tetramethyl derivative, which had almost the same melting point as the unsubstituted polyester. Second, the smectic mesophase of poly (butylene 4,4'-biphenyldicarboxylate) had changed into a nematic one (2-methylbutanediol) or completely disappeared (2,2-dimethyl, 2,3-dimethyl- and 2,2,3trimethylbutanediol). The tetramethyl derivative exhibited a birefringent melt, which could not be identified as a typical mesophase texture.

A poly (4,4'-biphenyldicarboxylate) with a nematic mesophase could also be obtained by copoly- 
merization using 1,4-butanediol and 2,2,3,3-tetramethylbutanediol as spacers.

The thermal stability of the poly (butylene $4,4^{\prime}$ biphenyldicarboxylates) was not much affected by the presence of 1-2 methyl side groups on the C-2 or C-3 atom of the diol spacer. When 4 methyl groups were present, the onset of thermal degradation was lowered although the temperature of maximum degradation rate had increased.

The authors thank Mr. P. J. L. Palmen for the rheological characterization, Mr. K. G. H. Raemaekers for performing the TGA measurements, Dr. P. E. Froehling for helpful suggestions in the polarized light microscopy studies, and Dr. C. E. Koning and Mr. G. H. Werumeus Buning for critically reviewing the manuscript (all from DSM Research). Dr. A. Turetskii (University of Twente) is acknowledged for performing the $\mathrm{X}$-ray analysis.

\section{REFERENCES AND NOTES}

1. I. Goodman and J. A. Rhys, Polyesters, Vol. 1, Iliffe Books, London 1965, Chap. 4.

2. V. V. Korshak and S. V. Vinogradova, Polyesters, J. Burdon, Ed., Pergamon Press, Oxford, 1965, Chap. 2 and 8.

3. P. Meurisse, C. Noel, L. Monnerie, and B. Fayolle, Br. Polym. J., 13, 55 (1981).

4. W. R. Krigbaum, J. Asrar, H. Toriumi, A. Ciferri, and J. Preston, J. Polym. Sci., Polym. Lett. Ed., 20, 109 (1982).

5. W. R. Krigbaum and J. Watanabe, Polymer, 24, 1299 (1983).

6. J. Watanabe and M. Hayashi, Macromolecules, 21, 278 (1988).

7. J. Watanabe and M. Hayashi, Macromolecules, 22, 4083 (1989).

8. W. J. Jackson, Jr. and J.C. Morris, in Liquid-Crystalline Polymers, ACS Symposium Series 435 (Miami Beach, FL 1989), R. A. Weiss and C. K. Ober, Eds., ACS Books, Washington, DC, 1990, p. 16.

9. E. Pérez, A. Bello, M. M. Marugán, and J. M. Pereña, Polym. Commun., 31, 386 (1990).

10. E. Pérez, E. Riande, A. Bello, R. Benavente, and J. M. Pereña, Macromolecules, 25, 605 (1992).

11. A. Bello, E. Pérez, M. M. Marugán, and J. M. Pereña, Macromolecules, 23, 907 (1990).

12. E. Pérez, R. Benavente, M. M. Marugán, A. Bello, and J. M. Pereña, Polym. Bull., 25, 413 (1991).

13. H. -B. Tsai, C. Lee, and N.-S. Chang, Polym. J. 24, 157 (1992).

14. E. Chiellini and G. Galli, in: Recent Advances in Mechanistic and Synthetic Aspects of Polymerization, M. Fontanille and A. Guyot, Eds., D. Reidel, Dordrecht, 1987, p. 425.
15. L. Bosio, B. Fayolle, C. Friedrich, F. Laupetre, P. Meurisse, C. Noel, and J. Virlet, in: Liquid Crystals and Ordered Fluids, Vol. 4, A. C. Griffin and J. F. Johnson, Eds., Plenum Press, New York, 1984, p. 401.

16. J. Lorente, C. Marco, M. A. Gómez, and J. G. Fatou, Polymer, 33, 202 (1990).

17. E. Chiellini, G. Galli, S. Carrozzino, and B. Gallot, Macromolecules, 23, 2106 (1990).

18. See note of reference 17 in reference 7.

19. W. R. Sorenson and T. W. Campbell, Preparative Methods of Polymer Chemistry, 2nd ed., J. Wiley \& Sons, New York, 1968, p. 97.

20. S. D. Cohen, C. A. Risinger Diuguid, J. C. Poirier, and J. K. Swadesh, Mol. Cryst. Liq. Cryst., 78, 135 (1981).

21. A. I. Vogel, Textbook of Practical Organic Chemistry, 4th ed., Longman Scientific \& Technical, New York, 1987 , p. 530.

22. M. Malanga and O. Vogl, J. Polym. Sci., Polym. Chem. Ed., 21, 2629 (1983).

23. Organic Synthesis, Collect. Vol. II, Wiley, New York, 1943, p. 264.

24. N. Petragnani and M. Yonashiro, Synthesis, 9, 710 (1980).

25. W. J. Jackson, Jr. and J. C. Morris, J. Appl. Polym. Sci., Appl. Polym. Symp., 41, 307 (1985).

26. B. C. Auman and V. Percec, Polymer, 29, 938 (1988).

27. B. Gordon III and A. E. Mera, Polym. Bull., 22, 379 (1989).

28. W. R. Krigbaum, J. Appl. Polym. Sci., Appl. Polym. Symp., 41, 105 (1985).

29. K. W. Doak and H. N. Campbell, J. Polym. Sci., 18, 215 (1955).

30. R. W. Lenz, Organic Chemistry of Synthetic High Polymers, Interscience, New York, 1967, p. 91.

31. Z. Florjanczyk, B. Deopura, R. S. Stein, and O. Vogl, J. Polym. Sci., Polym. Chem. Ed., 20, 1051 (1982).

32. J. R. Tuttle, H. E. Bartony, Jr., and R. W. Lenz, Polym. Eng. Sci., 27, 1156 (1987).

33. S. Onagi and T. Asada, Rheology, Vol 1, G. Astarita, G. Marucci, and L. Nicolai, Eds., Plenum Press, New York 1980, p. 127.

34. R. M. Lum, J. Polym. Sci., Polym. Chem. Ed., 17, 203 (1979).

35. G. Montaudo and C. Puglisi, Comprehensive Polymer Science, G. Allen and J. C. Bevington, Eds., Pergamon Press, Oxford, 1989, p. 237.

36. C. Botteghi, G. Ceccarelli, and G. Consiglio, J. Prakt. Chem., 314, 840 (1972).

37. T. W. Smith and G. B. Butler, J. Org. Chem., 43, 6 (1978).

38. E. Juaristi and J. S. Cruz-Sãnchez, J. Org. Chem., 53, 3334 (1988).

Received March 14, 1994

Accepted August 23, 1994 